\title{
As We May Remember
}

\author{
Alice Robbin, Roberta Lamb, John Leslie King and Jacques Berleur \\ Rob Kling Centre for Social Informatics, Indiana University, \\ arobbin@indiana.edu \\ University of California Irvine, rlamb@uci.edu \\ University of Michigan, jlking@si.umich.edu \\ University of Namur (Belgium), jberleur@info.fundp.ac.be
}

\section{Introduction}

By now, many retrospectives have been offered on Rob Kling. Some have focused on personal and professional reflections about what motivated his intellectual pursuit and shaped his socio-technical perspective. Others have looked carefully at the whole 'package' of Rob's work as a legacy of scholarly publications and a community of connected researchers who care about informatics and social worlds. His own characterization of his lifelong project was as an institution builder devoted to illuminating analytically understandings of the complex relationships between the design and use of advanced information and communication technologies (ICTs) and the character of social life in settings where people use them.

Many remembrances note that Rob was an idealist. His achievements, impressive and laudable as they were, have not yet produced a discipline as inclusive and socially realistic, nor an ICT-infused world that is as socially equitable, as Rob would have wished for. Our purpose in this short paper is to remember Rob as we knew him - warts and all - in our personal and professional lives. We have drawn together a series of historical links to events and influences that we know about to explain his approach, motivations, personal style and intellectual biases. 


\section{Remembrance as Reflection}

Our first memories are a reflection of Rob over time. At the time Rob began his career in the early 1970 s, discussions of the relationships between computers and society were largely speculative and prescriptive. There were relatively few computer systems and computer networks to serve as a basis for empirically anchored and analytically-oriented research, which he believed was required because social improvements do not always accompany substantial technological advances. Rob also believed that fundamental changes in science education were needed so that IT professionals would be trained to identify and evaluate the social consequences of ICT-based systems. Throughout his life he articulated a responsibility-centered role for information professionals that flowed from his convictions about the ethical self.

He was acutely mindful that technology was complicit in many aspects of human suffering, and he could not abide the dismissive or disinterested attitude of many technologists toward the growing body of empirical evidence that technology often had unintended negative consequences. He embraced a critical perspective that placed these contradictions at the heart of the technological conundrum. In executing his critical worldview, he opened the eyes of many people to the complexities of problems that seemed relatively simple on the surface. At the same time, however, many of Rob's zealous predictions about computerization failed.

Our reflections about the future of Social Informatics have begun to consider how he might have avoided some of the traps of a critical empirical approach. We remember heated arguments with Rob about socio-technical futures that stretched visions of computing to their logical (i.e. absurd) limits. But, perhaps due to inherent biases of critical and positivist perspectives, those limits were often simple linear extensions of the current context, rather than exponential or recursively accumulative imaginings of ICT-infused social worlds.

\section{Remembrance as Legacy}

We are cautiously mindful of the shortcomings that grew out of Rob's idealism, yet we are at the same time enormously admiring and appreciative of his overall legacy. Over the course of his life, Rob contributed insights from his wide-ranging empirical research and policy studies on computing, in more than a hundred articles and several books that were published in journals of diverse disciplines. He critically examined computing in the workplace. He wrote about the interactions between the public and organizations dependent on computer-based systems. He explored people's self conceptions in dealing with machines and about the computing world as a social institution. He was particularly attentive to the relationship between computing and public policy and, beginning with his first papers, addressed policy issues on privacy, the ethical dilemmas of computing, legal issues, and the social accountability of the IT professional. In one form or another his writings always addressed the normative implications of computerization, the roles and responsibilities of the public and private sectors and professions, and public policy design and its consequences for social life, work life, and the citizen. 
Through European colleagues in the early 1980s, he was introduced to the term 'social informatics' to describe this research area, and he adopted the term as a workable label to facilitate the integration of a heterogeneous body of research and to help communicate key theories and findings. By 1996, he had developed what he called a 'serviceable definition' of the discipline of Social Informatics, which he wrote 'refers to the interdisciplinary study of the design, uses and consequences of information and communication technologies that takes into account their interaction with institutional and cultural contexts." He intended that Social Informatics would be a genuine socio-technical systems perspective that included analytical, critical and normative approaches, multiple methodologies, innovations in research design, and true interdisciplinarity. His corpus of work introduced North American scholars to seven important social informatics ideas:

1. The context of ICT use directly affects their meanings and roles; the design of ICTs is linked to social and organizational dynamics.

2. ICTs are not value neutral; their use creates winners and losers.

3. ICT use leads to multiple, unexpected, and often paradoxical or time-dependent, effects (e.g. the 'paperless office' has actually generated more paper; and during the 1980 s and early 1990 s, the introduction of technology into the workplace did not appear to increase productivity).

4. ICT use has moral and ethical aspects, and these have social consequences.

5. ICTs are configurable 'packages'; they are actually collections of distinct components whose social use of similar components may lead to different technical networks in each social system.

6. ICTs follow trajectories that often favor the status quo. 7

7. ICTs co-evolve during design, development, and use, that is, before and after implementation.

Rob's institutional contribution was to educational program design that incorporated a study of society and technology, whose concepts he thought had been undervalued and unappreciated in science education. During the $1990 \mathrm{~s}$, concerned that various disciplines were not preparing their students to address the interdependencies of the social, the technical, and the ethical, he turned his attention to developing a program of critical inquiry for a Social Informatics education that would prepare IT professionals to respond appropriately and ethically in their future careers. This led to two editions of a reader designed for undergraduates, Computerization and Controversy, that was published along with an instructional manual for teachers ( $2^{\text {nd }}$ edition). His goal was to provide the conceptual foundation for a critical appreciation of the benefits and limitations provided by ICTs. He believed that IT professionals needed to understand that ICT is a socio-technical process and that social and organizational forces affected the functionality embedded in ICTs; that techniques needed to be developed to help identify and evaluate the social consequences of ICT-based systems. He also believed that information professionals needed to carefully consider elements of power and influence, resources available to and employed by various interests, and the consequences of their personal decisions and of public policies. And IT professionals needed to apply what he called 'person-centered standards' for the design of computerized information systems that promoted a sense of personal competence and authority. 
At the time of his death in May 2003, Rob had written the outline of a new book, provisionally entitled Computerization Within Societies: A Social Informatics Perspective. It was intended as a new conceptual synthesis of key ideas from social informatics research that would be translated into insightful ways of viewing the development, use and consequences of IT applications in workplaces, organizations, and institutional arenas. He wanted to explicitly articulate concepts and bring them alive with vivid illustrations, so that readers could "take them away" and apply them in their own life-worlds and their own research. The book would have a distinctive theoretical approach, one that treated ICTs as socio-technical networks, viewed the configuration of ICTs as situated in organizations or other social settings, and was also influenced by the relevant 'technological frames' that circulate through intersecting social worlds. Parts of the theoretical approach would come from neoinstitutional political sociology. However, his goal was to encourage readers to understand how socio-technical configurations play a role in influencing the range of common social behavior. The first chapters on discourses about ICTs and social change and the socio-technical character of ICTs were more conceptually oriented. Subsequent chapters would examine ICT applications, including computerization in workplaces and organizations, and transorganizational ICTs, such as dot-coms, scholarly communication and distance education. The book design concluded with a discussion of information societies in critical perspective.

\section{Remembrance as Vision}

Rob Kling's last book remains unfinished as a literary work, but its outline succinctly expresses his vision for the social informatics research community. Many of us who worked with Rob believe that his greatest gift was making us think differently - whether it was about something new, thinking in a new way, or adding back in some messy consideration that had been excluded intentionally. Through decades of intense, interpersonal, scholarly interaction, he played a unique, essential, and lasting role in the creation of a domain of research called Social Informatics. $\mathrm{He}$ contributed to a critical perspective on the nature, role, and dynamics of computerization. He was committed to empirical evidence and theoretical analysis. He challenged the assumptions about computerization -- his work a powerful indictment against the sloppy conjecture and hyperbolic statements about outcomes from computerization. He offered a convincing alternative interpretation of society and technology. Like Vannevar Bush's vision of the 'memex' device, Rob's vision of social informatics was based on in-depth, on-the-ground knowledge about what is, what is possible, but also what is likely - without knowing exactly how and when that vision might be realized. Maybe he overcompensated in his predictions for the tendencies toward technological determinism by other scholars of computing; but in so doing he developed a set of research skills in himself, his students and his colleagues for empirical inclusion, expansive consideration, concern for those left out, analytical synthesis, rapid characterization, and concrete conceptual anchorings of scholarly work. Above all, he perpetuated an idea that, through this kind of scholarship, we can develop an informatics know-how that curbs our enthusiasm 
about the technologies we love just enough to really implement better social worlds. To paraphrase Bush, Kling's social informatics disciplinary 'device' would be capable of

...making more accessible our bewildering store of knowledge about ICTs in social contexts; it would help us establish a new relationship between thinking professionals, the sum of our knowledge, and the implications of our actions.

This conference honors Rob Kling's legacy and his vision. It is a testament to his commitment and to the relevance of his ideas about the value of Social Informatics. 